\title{
Development of Variable Speed Wind Turbines Connected to Grid for Optimum Utilization and Power Quality Improvement using Seven-Level Inverter
}

\author{
Shwetha C M' $\mathbf{M}^{1}$ S Aprameya ${ }^{2}$ \\ PG Student, Dept. of Electrical Engineering, University BDT College of Engg., Davangere, India ${ }^{1}$ \\ Associate Professor, Dept. of Electrical Engineering, University BDT College of Engg, Davangere, India ${ }^{2}$
}

\begin{abstract}
This paper presents an improvement technique for the power quality of the electrical part of a wind generation system with a Permanent magnet synchronous generator (PMSG) which aims to optimize the utilization of wind power injected into weak grids. To realize this goal, an uncontrolled rectifier-digitally controlled inverter system is proposed. The advantage of the proposed system is its simplicity due to fewer controlled switches which leads to less control complexity. It also provides full control of active and reactive power injected into the grid using a voltage source inverter (VSI) as a dynamic volt ampere reactive (VAR) compensator. A voltage oriented control (VOC) scheme is presented in order to control the energy to be injected into the grid. In an attempt to minimize the harmonics in the inverter current and voltage and to avoid poor power quality of the wind energy conversion system (WECS), an LC filter is inserted between VOC VSI and the grid. MPPT controllers used for extracting maximum possible power in WECS. Simulation is carried out using MATLAB Simulink.
\end{abstract}

Keywords: Permanent magnet synchronous generator (PMSG), voltage source inverter (VSI), dynamic volt ampere reactive (VAR) compensator, voltage oriented control (VOC), wind energy conversion systems (WECS), maximum power point tracking (MPPT).

\section{INTRODUCTION}

The WIND system is rapidly developing as one of the most promising renewable energy resources over the world. The penetration of this system is very important to solving global warming and the exhaustion of fossil fuel. In order to optimize the wind turbine system, many kinds of power conversion systems to connect between the generator and the grid line have been proposed and utilized [1].

Nonlinear devices, such as power electronics converters, are injecting harmonic currents in the ac system and increase the overall reactive power demanded by the equivalent load. Also, the number of sensitive loads that require ideal sinusoidal supply voltages for their proper operation has increased [2].

We do believe that there is still room to improve the power quality for grid-connected wind energy conversion systems (WECSs) to obtain more economical systems. In order to keep power quality under limits proposed by standards, it is necessary to include compensation.

A three-phase ac-to-dc resonant converter operating in high input power factor mode has been introduced in [1]. This design offers several advantages such as high power factor and low THD operation. However, high switching losses for high frequency operation will reduce the overall efficiency.

Reference [1] proposed a power electronic converter with a simple open-loop feed forward control technique designed for small-scale wind energy systems. This technique has improved the system efficiency at low wind speeds which expands the wind turbine operating range. An uncontrolled diode rectifier and dc-dc converter were employed as an interface part between wind turbine and dc-load. An efficient wind generator control technique has been developed using -current control loops. The main objective was to achieve maximum power from the generation side.

Today, the voltage oriented control (VOC) technique, which guarantees high dynamics and static performance via internal current control loops, has become very popular and has constantly been developed and improved. 


\section{International Journal of Innovative Research in Electrical, Electronics, Instrumentation and Control Engineering}

\section{ISO 3297:2007 Certified}

Vol. 5, Issue 5, May 2017

This method depends on using conventional proportional and integral (PI) compensators in the rotating reference frame to produce its control input commands. However, the conventional -controllers have the inherent drawbacks that its response is somewhat slower for very fast transients and its control range is limited because of its fixed gains but it still can be improved using the good design for its gain parameters.

In this paper, a permanent magnet synchronous generator (PMSG)-based WECS with VOC strategy for a three-phase voltage-source PWM inverter is proposed as a dynamic volt ampere reactive (VAR) compensator system for weak grids. A second-order software phase-locked loop (SPLL) for phase angle detection of the grid voltage in synchronous reference frame is proposed. An analytical model for the voltage source inverter (VSI) connected to the grid with LC filter and the operating principle of the proposed vector controllers are introduced.

\section{POWER CHARACTERISTICS OF WIND TURBINE}

Wind turbine is a non-linear system whose output depends on various parameters such as wind velocity, dimensions of the wind turbine and tip speed ratio. The output of the wind turbine is given by the following equation

$$
\mathrm{P}=1 / 2 \mathrm{C}_{\mathrm{p}} \rho \mathrm{Av} \mathrm{v}^{3}
$$

Where, $\mathrm{C}_{\mathrm{p}}$ - power co-efficient, $\rho$ - air density, A - swept area of the wind turbine, $\mathrm{V}$ - wind speed.

The value of ideal power is limited by what is known as Betz coefficient with a value of $C_{P}=0.59$ as the highest possible conversion efficiency possible. In practice, most wind turbines have efficiencies have efficiencies well below 0.5 depending on type, design and operational conditions.

Cpis the wind power coefficient (denotes power extraction efficiency which is a function of $\beta$ and $\lambda$, $\beta$ being the pitch angle and $\lambda$ being the tip speed ratio - TSR given by $R \Omega / v$ where R is turbine radius, $\Omega$ is turbine shaft speed). Thus, power captured by the wind turbine is heavily dependent upon TSR when $\beta$ is unchanged. The power conversion efficiency has a well determined maximum $\mathrm{Cp}$, max for a specific tip speed ratio $\lambda$. The optimal control of active power in a variable-speed fixed-pitch WECS can therefore be easily achieved, if $\lambda$ is controlled for attaining the Cp,max corresponding to a given wind velocity [10]-[12]. From equation (1), it follows that

$$
\mathrm{Pwt}=0.5 \mathrm{Cp}(\lambda, \beta) \rho \pi \mathrm{R} 2 \mathrm{v} 3=0.5\{\mathrm{Cp}(\lambda) / \lambda 3\} \rho \pi \mathrm{R} 5 \Omega 3
$$

Thus the torque produced by the turbine is computed as

$$
\text { Twt }=\text { Pwt } / \Omega
$$

Hence the torque produced by the turbine is proportional to $\Omega 2$ and power is proportional to $\Omega 3$. So, by the above equations it can be seen that for a particular TSR, the power extracted by the turbine is maximum for a given wind velocity.

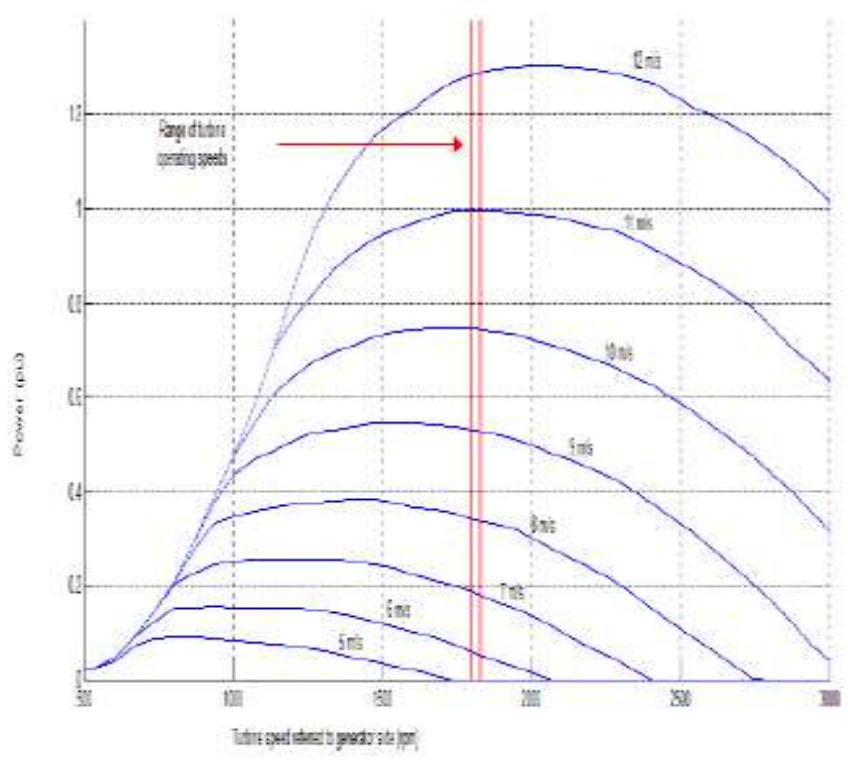

Fig.1. Power curves of a typical wind turbine 
This is equivalent to maintaining the tip speed ratio at its optimal value $\lambda$ opt and can be achieved by operating the turbine at a variable speed, corresponding to the wind speed. Fig. 1 represents the power curves of a typical wind turbine of wind energy conversion system (WECS) [2].

\section{METHODOOLOGY}

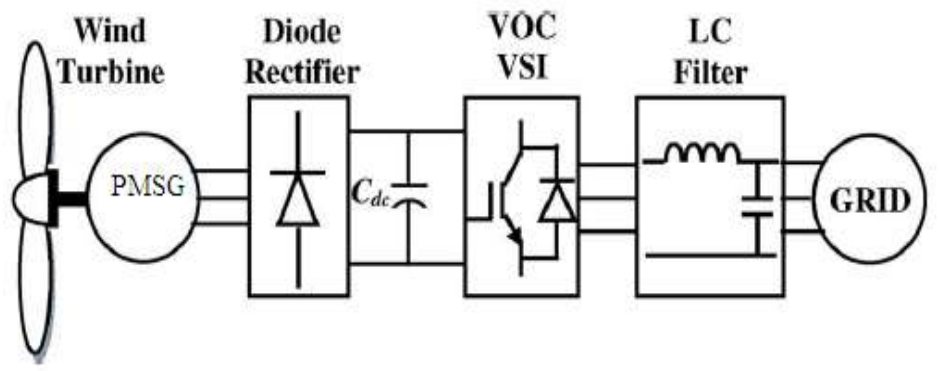

Fig.2. Proposed PMSG-based WECS with VOC VSI

The proposed topology is shown in Fig. 2. The advantages of the proposed system over the previous traditional systems are that:

- it has a simpler circuit and less complexity

- higher efficiency, since there are no switches in the rectifier stage

- reliability of the system is greatly improved, because it has the ability of full active and reactive power control

- higher injected power quality is achieved by employing LC filter between the inverter and grid

- better dynamic performance under different possible conditions, by using decoupled VOC control scheme

\section{SYSTEM PERFORMANCE}

\section{A. Rectifier}

A rectifier is an electrical device that converts alternating current $[\mathrm{AC}]$, which periodically reverses direction, to direct current [DC], which flows in only one direction. The rectifier here used is Un-controlled rectifier [3]. The rectified output is given to DC link capacitor.

\section{B. DC Link Capacitor}

A DC link is the connection which connects a rectifier and an inverter. The DC link usually has a capacitor known as the DC link capacitor. This capacitor is connected in parallel between the positive and negative conductors. These capacitors help in preventing the transients from the load side from going back to the distribution side. It also serves to smoothen the pulses in the rectified DC.

\section{VOC VSI as Dynamic Var Compensator}

The inverter is the power electronic circuit which converts DC voltage into AC voltage. The DC source is normally a battery or output of the controlled rectifier. Voltage source inverters (VSI) are commonly used to transfer real power source to an AC load.

Until recently, most wind power plant and utility have utilized capacitor banks to correct power factor to near unity. The capacitors are switched in and out by means of mechanical contactors [4]. Unfortunately, because these contactors are relatively slow, they are unable to react to sudden momentary dips in voltage commonly seen in weak grid and can add greater stress to the utility grid. VOC VSI is proposed here as a dynamic VAR compensator system.

Dynamic VAR systems detect and instantaneously compensate for voltage disturbances by injecting leading or lagging reactive power at key points on power transmission grids. Through the VAR control system, reactive power is supplied to the grid in a fraction of a second, regulating the system voltage and stabilizing the weak grid.

\section{LC filter}

To mitigate the harmonics present in the output of the inverter an LC filter is inserted between the voltage source inverter and the grid. By removing the distortions present in the output, quality of the output power can be improved. 


\section{SIMULINK MODEL}

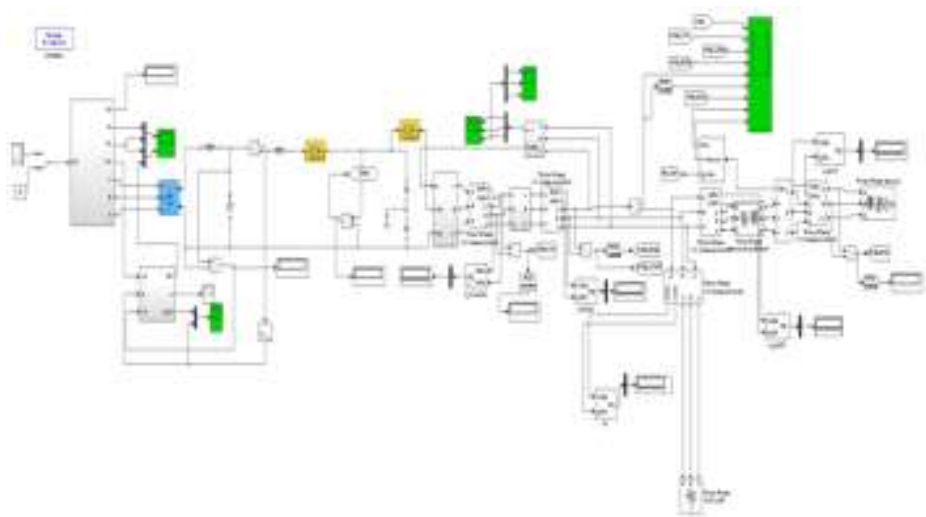

Fig.3. Simulink model of PMSG-based WECS with VOC VSI

VI. RESULTS

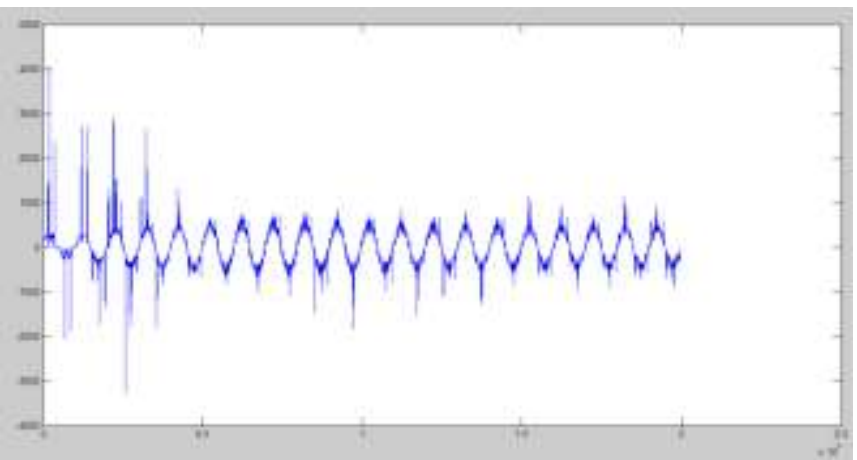

Fig.1. Inverter voltage

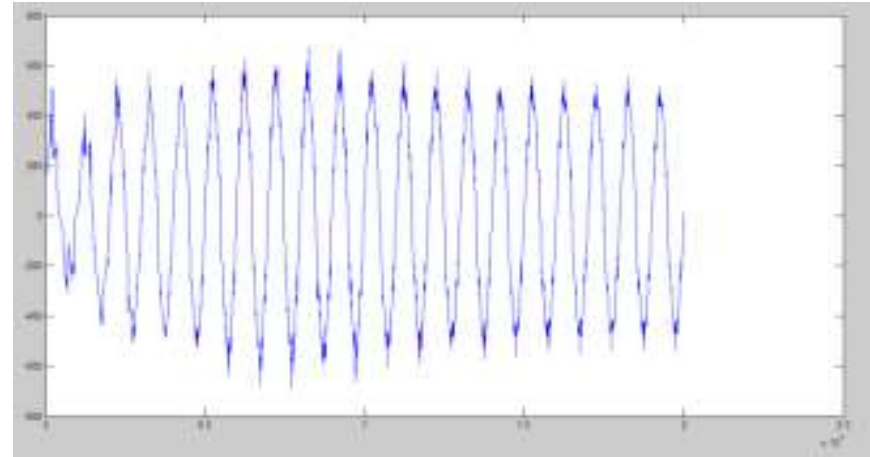

Fig.2. Grid voltage

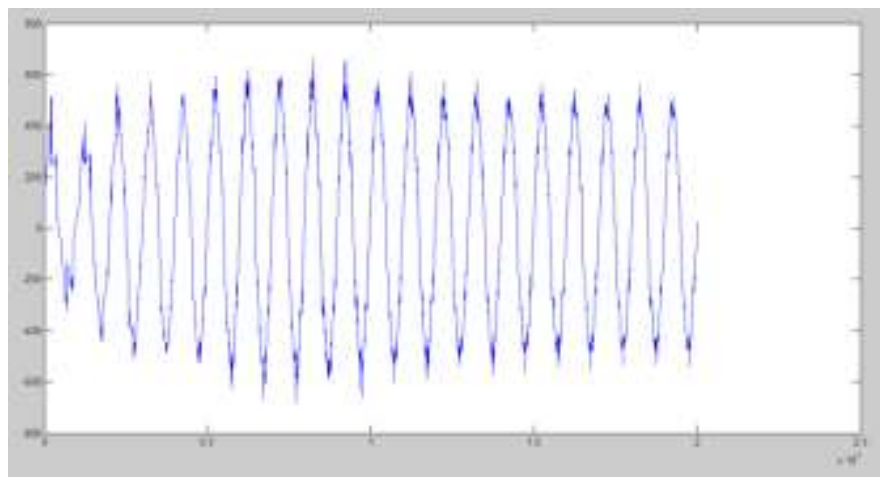

Fig.3. Load voltage 


\section{CONCLUSION}

A Permanent Magnet Synchronous Generator (PMSG) is proposed in this paper to optimize the utilization of wind power which is injected into the weak grids. A simpler system is proposed, that involves an uncontrolled rectifier, digitally controlled inverter system in order to realize this goal. In an attempt to minimize the harmonics in the inverter current and voltage, an LC filter is inserted between VOC, VSI and the grid. Using MATLAB/Simulink the simulation is done. The results obtained are a proof for the efficiency and reliability of the proposed paper. This system is sustainable to enhance the power quality of the wind energy conversion system (WECS).

\section{REFERENCES}

[1] Hao, Anjun Xi, Shuju Hu, Nianhong Li, Honghua Xu., IEEE PES ASIA 20121569527141

[2] Mahmoud M.Amin and Osama A. Mohammed, "Development of high-performance grid-connected wind energy conversion system for optimumutilization of variable speed wind turbines" IEEE transactions on sustainable energy, vol. 2, no. 3, july 2011 (references)

[3] Magdi Ragheb and Adam M. Ragheb., Wind turbines theory - the betz equation and optimal rotor tip speed ratio., www.intechopen.com

[4] Khondaker Tasrif Noor and MD. Samiul Islam., "Analysis of power converters and smart power factor correction"., Dhaka,Bangladesh., 2016.

\section{BIOGRAPHIES}

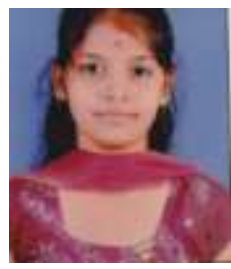

Shwetha C M Obtained BE degree from VTU in 2015. Currently pursuing master degree in University BDT College of Engineering, Davangere, Karnataka, India.

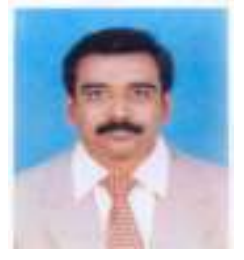

K.S. Aprameya obtained his BE degree in electrical and electronics engineering in 1989 , M.Tech degree in digital electronics and communication systems in 1993 ,from University of Mysore and awarded Ph.D degree in 2009 from Indian Institute of Technology, Roorkee. He is a life member for ISTE, New Delhi , MIE for "The Institution of Engineers (India)" and a member for Ultrasonic Society of India, National Physical Laboratory, New Delhi. He worked as Honorary Secretary for The Institution of Engineers (India) Davangre Local Centre, Karnataka, India (2012-14). He is currently interested in image processing and its applications and ultrasonic instrumentation systems. 